\title{
Effects of deficit irrigation with saline water on spring wheat growth and yield in arid Northwest China
}

\author{
Jing JIANG ${ }^{1,2}$, ZaiLin $\mathrm{HUO}^{2 *}$, ShaoYuan $\mathrm{FENG}^{3}$, ShaoZhong KANG ${ }^{2}$, FenXing WANG ${ }^{2}$, \\ ChaoBo ZHANG ${ }^{1}$ \\ ${ }^{1}$ College of Water Science and Engineering, Taiyuan University of Technology, Taiyuan 030024, China; \\ ${ }^{2}$ Centre for Agricultural Water Research in China, China Agricultural University, Beijing 100083, China; \\ ${ }^{3}$ College of Water Science and Engineering, Yangzhou University, Yangzhou 225009, China
}

\begin{abstract}
Field experiments were conducted in 2008 and 2009 to study the effects of deficit irrigation with saline water on spring wheat growth and yield in an arid region of Northwest China. Nine treatments included three salinity levels $\mathrm{s} 1, \mathrm{~s} 2$ and $\mathrm{s} 3(0.65,3.2$, and $6.1 \mathrm{dS} / \mathrm{m})$ in combination with three water levels $\mathrm{w} 1$, w2 and $\mathrm{w} 3(375,300$, and $225 \mathrm{~mm}$ ). In 2008, for most treatments, deficit irrigation showed adverse effects on wheat growth; meanwhile, the effect of saline irrigation was not apparent. In 2009, growth parameters of w1 treatments were not always optimal under saline irrigation. At 3.2 and $6.1 \mathrm{dS} / \mathrm{m}$ in 2008 , the highest yield was obtained by w1 treatments, however, in 2009 , the weight of 1,000 grains and wheat yield both followed the order w2 $>w 1>w 3$. In this study, spring wheat was sensitive to water deficit, especially at the booting to grain-filling stages, but was not significantly affected by saline irrigation and the combination of the two factors. The results demonstrated that $300-\mathrm{mm}$ irrigation water with a salinity of less than $3.2 \mathrm{dS} / \mathrm{m}$ is suitable for wheat fields in the study area.
\end{abstract}

Keywords: saline water irrigation; leaf area index (LAI); leaf potential; yield components

Citation: Jing JIANG, ZaiLin HUO, ShaoYuan FENG, ShaoZhong KANG, FenXing WANG, ChaoBo ZHANG. 2013. Effects of deficit irrigation with saline water on spring wheat growth and yield in arid Northwest China. Journal of Arid Land, 5(2): 143-154.

Increased agricultural production has become an urgent requirement of the expanding world population (Howell, 2001; Chen et al., 2011). Yet, there has been a continued decrease in available fresh water that can be used by agricultural production (Cai and Rosegrant, 2003). At the same time, the quality of irrigation water has also deteriorated. As a result, both deficit irrigation and saline irrigation have been prevalently used in agriculture.

Saline water has been used successfully for agricultural irrigation (Ayars et al., 1993; Shalhevet, 1994; De Pascale and Barbieri, 1995; Ben-Asher et al., 2006a, b; Ould Ahmed et al., 2007). Crop yield is the most important consideration in the utilization of saline water (Katerji et al., 1998; Tedeschi and Menenti, 2002; Malash et al., 2005). According to soil salinity, wheat is classified to be salt tolerant (Maas and Hoffman, 1977; Katerji et al., 2000). Khosla and Gupta (1997) found that wheat height and yield increased with irrigation amount under drained conditions, but they were decreased under undrained conditions. Datta et al. (1998) pointed out that yields do not always increase with the rise in irrigation quantity under saline conditions.

Generally, an appropriate deficit irrigation system with fresh water can increase irrigation efficiency without significantly decreasing yield (Mao et al., 2003; Panda et al., 2003; Farré and Faci, 2006). Responses of wheat growth to water deficits vary depending on wheat species and growth stages. Jalota et al. (2006) reported that the anthesis to grain development period is the most sensitive stage to water stress

*Corresponding author: ZaiLin HUO (E-mail: huozl@cau.edu.cn) 
in wheat in Northwest India. In China, Zhang et al. (2006) concluded from experiments that water stress should be avoided at the booting and heading of spring wheat. In addition, growth parameters have manifested certain differences during deficit irrigation. Zhang et al. (1998) found that leaf area index (LAI), the size of upper leaves, the length of base internodes and grain yield significantly decreased when irrigation was reduced from four normal applications to only one, but kernel number per panicle was not decreased.

Crop growth parameters and yield under combined deficit and saline water irrigation were different to those under separate deficit or saline irrigation. Ayers and Westcot (1985) reported that the combination of drought and salinity reduced the water availability for crops at a more significant rate than the separate effect of either salinity or drought alone. Shani and Dudley (2001) stressed that the maximum yield and the corresponding irrigation water quantity for poor quality water were less than those for good quality water. Therefore, crop growth under deficit irrigation with saline water should be further investigated.

Shiyang River Basin is an arid region in Northwest China. Groundwater is the main water resources for agriculture in this region. Over-exploitation of groundwater resources from shallow and deep aquifers in this area has led to a decline of the groundwater table and an increase in groundwater salinity. As a result, there is no sufficient fresh water for agricultural irrigation. Consequently, saline water for deficit irrigation has to be taken into account. The objectives of this study were: (1) to investigate the soil water content and soil salinity for different water and salinity treatments; (2) to investigate the interacted effects of deficit and saline water irrigation on wheat growth parameters (i.e. pre-dawn leaf potential, plant height and leaf area index); and (3) to study the interacted effects of deficit and saline water irrigation on spring wheat yield and yield components.

\section{Materials and methods}

\subsection{Site description and experimental design}

The experiment was conducted from March 2008 to July 2009 at the Experimental Station for Water-saving in Agriculture and Ecology of China Agricultural University (ESWAE-CAU) $\left(102^{\circ} 52^{\prime} \mathrm{E}\right.$, $\left.37^{\circ} 52^{\prime} \mathrm{N}\right)$ located in Shiyang River Basin, Northwest China. The experimental region is a typical arid desert area with a temperate dry climate, an annual sunshine duration of over $3,000 \mathrm{~h}$, an average annual precipitation of around $160 \mathrm{~mm}$, and an open annual water evaporation of about $2,000 \mathrm{~mm}$. The physical-chemical properties of each layer in a soil profile were presented in Table 1.

Reference evapotranspiration from 2005 to 2007 was calculated with meteorological data using the Penman-Monteith formula. The average evapotranspiration $\mathrm{ET}_{\mathrm{c}}(375 \mathrm{~mm})$ for the three years was used for the reference to control irrigation levels in the study. Irrigation was applied with three salinity levels of $0.65 \mathrm{dS} / \mathrm{m}$ (s1), $3.2 \mathrm{dS} / \mathrm{m}(\mathrm{s} 2)$ and $6.1 \mathrm{dS} / \mathrm{m}$ (s3), and three water quantity levels of $100 \% \mathrm{ET}_{\mathrm{c}}(375 \mathrm{~mm}), 80 \%$ $\mathrm{ET}_{\mathrm{c}}(300 \mathrm{~mm})$ and $60 \% \mathrm{ET}_{\mathrm{c}}(225 \mathrm{~mm})$. One hundred percent $\mathrm{ET}_{\mathrm{c}}(\mathrm{w} 1)$ represents sufficient irrigation, while $80 \% \mathrm{ET}_{\mathrm{c}}(\mathrm{w} 2)$ and $60 \% \mathrm{ET}_{\mathrm{c}}(\mathrm{w} 3)$ indicate deficit irrigation. Surface irrigation was applied four times according to local farming customs, specifically, at tiller to jointing, jointing to heading, heading to grain-filling, and grain-filling to maturity stages (Table 2).

Nine treatments with three replicates were laid out in a split plot design to test the wheat growth and

Table 1 Physical-chemical properties of the soil before the experiment

\begin{tabular}{|c|c|c|c|c|c|c|c|c|c|c|}
\hline \multirow[t]{2}{*}{$\begin{array}{l}\text { Depth } \\
(\mathrm{cm})\end{array}$} & \multirow[t]{2}{*}{$\begin{array}{l}\text { Textural } \\
\text { class }\end{array}$} & \multirow[t]{2}{*}{$\begin{array}{l}\text { Bulk density } \\
\quad\left(\mathrm{g} / \mathrm{cm}^{3}\right)\end{array}$} & \multirow[t]{2}{*}{$\begin{array}{l}\text { Field capacity } \\
\qquad\left(\mathrm{cm}^{3} / \mathrm{cm}^{3}\right)\end{array}$} & $\begin{array}{c}\text { Organic } \\
\text { matter }\end{array}$ & Total N & Total P & Total K & \multirow[t]{2}{*}{$\begin{array}{c}\mathrm{CEC} \\
(\mathrm{mmol} / \mathrm{kg})\end{array}$} & \multirow{2}{*}{$\begin{array}{l}\text { Soil salinity } \\
\mathrm{EC}_{\mathrm{e}}(\mathrm{dS} / \mathrm{m})\end{array}$} & \multirow[t]{2}{*}{$\mathrm{pH}$} \\
\hline & & & & \multicolumn{4}{|c|}{$\mathrm{g} / \mathrm{kg}$} & & & \\
\hline $0-20$ & Sandy loam & 1.56 & 0.22 & 7.86 & 0.477 & 0.685 & 15.80 & 271 & 1.09 & 8.70 \\
\hline $20-50$ & Sandy loam & 1.61 & 0.24 & 6.66 & 0.338 & 0.403 & 16.00 & 273 & 0.92 & 8.68 \\
\hline $50-85$ & Clay loam & 1.38 & 0.32 & 6.72 & 0.412 & 0.857 & 17.40 & 294 & 1.40 & 8.64 \\
\hline $85-125$ & Loam & 1.41 & 0.31 & 2.64 & 0.213 & 0.463 & 18.70 & 281 & 1.67 & 8.71 \\
\hline $125-150$ & Silt clay & 1.49 & 0.38 & 4.67 & 0.397 & 0.560 & 22.00 & 277 & 1.62 & 8.46 \\
\hline
\end{tabular}


Table 2 Detailed irrigation schedule of each treatment

\begin{tabular}{|c|c|c|c|c|c|c|}
\hline \multirow[t]{2}{*}{ Treatment } & \multirow{2}{*}{$\begin{array}{l}\text { Salinity level } \\
\quad(\mathrm{dS} / \mathrm{m})\end{array}$} & Irrigation amounts & Tiller to jointing stage & Jointing-heading stage & $\begin{array}{l}\text { Heading to grain-filling } \\
\text { stage }\end{array}$ & $\begin{array}{l}\text { Grain-filling to } \\
\text { maturity stage }\end{array}$ \\
\hline & & \multicolumn{5}{|c|}{$\mathrm{mm}$} \\
\hline w1-s1 & 0.65 & 375 & 90 & 97.5 & 105 & 82.5 \\
\hline $\mathrm{w} 1-\mathrm{s} 2$ & 3.20 & 375 & 90 & 97.5 & 105 & 82.5 \\
\hline w1-s3 & 6.10 & 375 & 90 & 97.5 & 105 & 82.5 \\
\hline w2-s1 & 0.65 & 300 & 72 & 78.0 & 84 & 66.0 \\
\hline w2-s2 & 3.20 & 300 & 72 & 78.0 & 84 & 66.0 \\
\hline w2-s3 & 6.10 & 300 & 72 & 78.0 & 84 & 66.0 \\
\hline w3-s1 & 0.65 & 225 & 54 & 58.5 & 63 & 49.5 \\
\hline w3-s2 & 3.20 & 225 & 54 & 58.5 & 63 & 49.5 \\
\hline w3-s3 & 6.10 & 225 & 54 & 58.5 & 63 & 49.5 \\
\hline
\end{tabular}

Note: w1, w2 and w3 denote water levels of $100 \%, 80 \%$, and $60 \% \mathrm{ET}_{\mathrm{c}}$, respectively; s1, s2 and s3 denote water salinity levels of $0.65,3.2$ and $6.1 \mathrm{dS} / \mathrm{m}$, respectively.

water productivity. There were 27 micro-plots in total. Each micro-plot was $3.0 \mathrm{~m} \times 4.0 \mathrm{~m}$. Bunds with a height of $0.3 \mathrm{~m}$ to reinforce the surrounding and protective area and a width of $1.5 \mathrm{~m}$ to minimize horizontal water movement were placed around the micro-plots. Fresh water with a salinity of $0.65 \mathrm{dS} / \mathrm{m}$ was obtained from a local well. The fresh water contained the following ions (in $\mathrm{mg} / \mathrm{L}$ ): $\mathrm{Na}^{+}+\mathrm{K}^{+}=129.758$, $\mathrm{Mg}^{2+}=45.715, \mathrm{Ca}^{2+}=31.925, \mathrm{SO}_{4}{ }^{2-}=296.225, \mathrm{HCO}_{3}{ }^{-}=$ 41.194 and $\mathrm{Cl}^{-}=150.192$. According to the composition of local groundwater, saline water of 3.2 and 6.1 $\mathrm{dS} / \mathrm{m}$ was prepared artificially by dissolving $\mathrm{NaCl}$, $\mathrm{MgSO}_{4}$ and $\mathrm{CaSO}_{4}$ (a mass ratio of $2: 2: 1$ ) in fresh water, respectively.

Wheat at seed quantity $525 \mathrm{~kg} / \mathrm{hm}$ and row spacing of $15 \mathrm{~cm}$ was sown every 19 March and harvested every 15 July for each year. The name of the wheat variety is Yongliang 4. The fertilizer amounts before planting for each plot were $0.585-\mathrm{kg} \mathrm{NH}_{4} \mathrm{H}_{2} \mathrm{PO}_{4}$, $0.360-\mathrm{kg} \mathrm{CO}\left(\mathrm{NH}_{2}\right)_{2}, 0.090-\mathrm{kg} \mathrm{K}$ and $0.029-\mathrm{kg} \mathrm{Zn}$. When necessary, cultural practices, such as pest control, harrowing, and fertilization were executed following local experience.

\subsection{Weather recording and sampling methods}

An automatic meteorological station (Weather Hark, Campbell Scientific, USA) was installed in the experimental station. Precipitation, relative humidity, wind speed, maximum and minimum air temperature, and solar radiation were measured and stored at an hourly basis. Daily mean temperature during the growing season (March to July) ranged from $-5.3-36.6^{\circ} \mathrm{C}$ in 2008 and $-7.3-33.6^{\circ} \mathrm{C}$ in $2009 . \mathrm{Cu}-$ mulative solar radiation for 2008 and 2009 were 2,495 and $2,288 \mathrm{MJ} / \mathrm{m}^{2}$, respectively. Total effective precipitation $(\geq 2.5 \mathrm{~mm}$ ) during the spring wheat growth period was $27.8 \mathrm{~mm}$ (occurring four times at days 23, 33, 49 and 101 after sowing) in 2008 and $25.4 \mathrm{~mm}$ (occurring five times at days 42, 55, 69, 91 and 110 after sowing) in 2009.

Crop developmental stages were recorded as presented in Table 3. Plant height, leaf area index and pre-dawn leaf water potential were measured at the successive phenological stages. For each treatment, plant height was measured by a tapeline from soil surface to the highest apex (before heading) or to the crest of the spike (excluding awn, after heading); five to ten measurement replicates were carried out in each plot. LAI was estimated by the SUNSCAN Canopy Analysis System (SUNSCAN, Delta, UK). Transmeridional and south-north LAI were separately determined, and the average values were used in three replicates per treatment. Pre-dawn leaf water potential was measured by a PSYPRO water potential system (WESCOR Inc., Logan, Utah, USA) on three leaves per treatment; they were taken from the upper part of the canopy before dawn on sunny days. After harvest, yield components, such as above-ground biomass, the number of ears per plant, and the number and weight of grains per ear, were determined by the averages of 20 plants per plot. The weight of 1,000 grains for each plot was determined by three replicates. A grain yield of $1 \mathrm{~m}^{2}$ in each plot was measured to determine yield per hectare.

Soil samples from each treatment were taken throughout the growing season every 15-20 days at a $10-\mathrm{cm}$ interval down to $20 \mathrm{~cm}$ and a $20-\mathrm{cm}$ interval down to $120-\mathrm{cm}$ soil depth. Each soil sample was 
Table 3 Phenological stages of spring wheat and irrigation time (in the number of days after sowing)

\begin{tabular}{|c|c|c|c|c|c|c|}
\hline \multicolumn{2}{|c|}{ Phenological stages } & $\begin{array}{c}\text { Emergence to } \\
\text { tillering }\end{array}$ & $\begin{array}{c}\text { Tillering to } \\
\text { jointing }\end{array}$ & $\begin{array}{l}\text { Jointing to } \\
\text { heading }\end{array}$ & $\begin{array}{l}\text { Heading to } \\
\text { grain-filling }\end{array}$ & $\begin{array}{l}\text { Grain-filling to } \\
\text { maturity }\end{array}$ \\
\hline & & $13-27$ & $28-46$ & $47-73$ & $74-98$ & $99-118$ \\
\hline \multirow{2}{*}{ Irrigation time } & 2008 & - & 46 & 72 & 94 & 105 \\
\hline & 2009 & - & 38 & 57 & 77 & 99 \\
\hline
\end{tabular}

divided into two parts. One part was used for measuring soil water content and the other part for measuring soil salinity. Soil water content was determined gravimetrically, and volumetric soil water content was obtained by multiplying gravimetric water content with soil bulk density. Another part of soil sample was air-dried, ground and passed through a 2-mm sieve. Then, the electrical conductivity of 1:5 soil-water extract $\left(\mathrm{EC}_{1: 5}\right)$ was measured. The $\mathrm{EC}_{1: 5}$ was then converted to the electrical conductivity of saturated paste $\left(E C_{\mathrm{e}}\right)$ with the equation $E C_{\mathrm{e}}=12.15 E C_{1: 5}-1.3064$. The volumetric soil water contents at $110-120$ and 120-130 cm used for estimating deep percolation were measured every 3-7 days using a portable soil moisture monitoring system (Diviner 2000, Sentek Pty. Ltd., South Australia).

\subsection{Harvest index and harvest ratio}

Harvest index (HI) was calculated as $H I=G Y$ / $(G Y+S Y)$, while harvest ratio (HR) was calculated as $H R=G Y / S Y$, where $G Y$ is the grain yield per plant $(\mathrm{g})$ and $S Y$ is the straw yield per plant $(\mathrm{g})$.

\subsection{Data analysis}

Analysis of variance (ANOVA) was employed to evaluate the effect of water quality and quantity, and their interaction on crop growth and yield component. Tukey's test was used to test the difference between groups in water quantity and quality $(P<0.05)$. Data were analyzed with the SPSS 16.0 software package (SPSS Inc., Chicago, IL, USA).

\section{Results}

\subsection{Soil water and salt content}

Figures 1 and 2 show the average soil water content and salt content of $0-120 \mathrm{~cm}$ depth during the wheat growth period. Through the growth period, soil water contents of $\mathrm{w} 3$ treatments were significantly lower $(P<0.05)$ than $\mathrm{w} 2$ and $\mathrm{w} 1$ treatments irrespective of irrigation water salinity and year. The effect of saline irrigation on soil water content was not significant. The moderate soil water content is about $60 \%-80 \%$ of the field capacity. In this study, field capacity of $0-120 \mathrm{~cm}$ soil layer was $28 \%$, thus the corresponding moderate soil water content was $16 \%-24 \%$. It can be found that soil water content of w3 treatments from 60 days after sowing in 2008 was lower than 16\%. However, the effects of saline and deficit irrigation on soil salt content were both significant $(P<0.05)$. Salt content increased with increasing irrigation water salinity and quantity. The salt contents of $w 1-s 3$ treatments were more than $1.5 \mathrm{~g} / \mathrm{kg}$, and other treatments all got values of less than $1.5 \mathrm{~g} / \mathrm{kg}$ in both years. Deficit irrigation effectively reduced salt accumulation at the same water salinity level, especially at higher water salinity (s2 and s3). Paired-samples t test was conducted to evaluate the difference of soil water content and soil salinity in two years. The results showed that there were no significant difference between soil water contents in 2008 and 2009. However, soil salinity in 2009 was significant higher than that in 2008 in saline treatments.

\subsection{Plant growth}

\subsubsection{Pre-dawn leaf water potential}

The pre-dawn leaf water potential can be used to indicate the water stress of plants (van Hoorn et al., 1993; Katerji et al., 1998). Figure 3 was presented to compare pre-dawn leaf water potential under saline and deficit irrigation. Pre-dawn leaf potential showed a typical trend of increase after irrigation and decrease during intervals between two successive irrigations, which is similar to reported literature (van Hoorn et al., 1993; Katerji et al., 2009). Curves of pre-dawn leaf potential during the two-year study showed a different shape, which was induced by different irrigation time and sampling dates. Lower pre-dawn leaf potential in early 2008 could be explained by the delay of the first irrigation. 

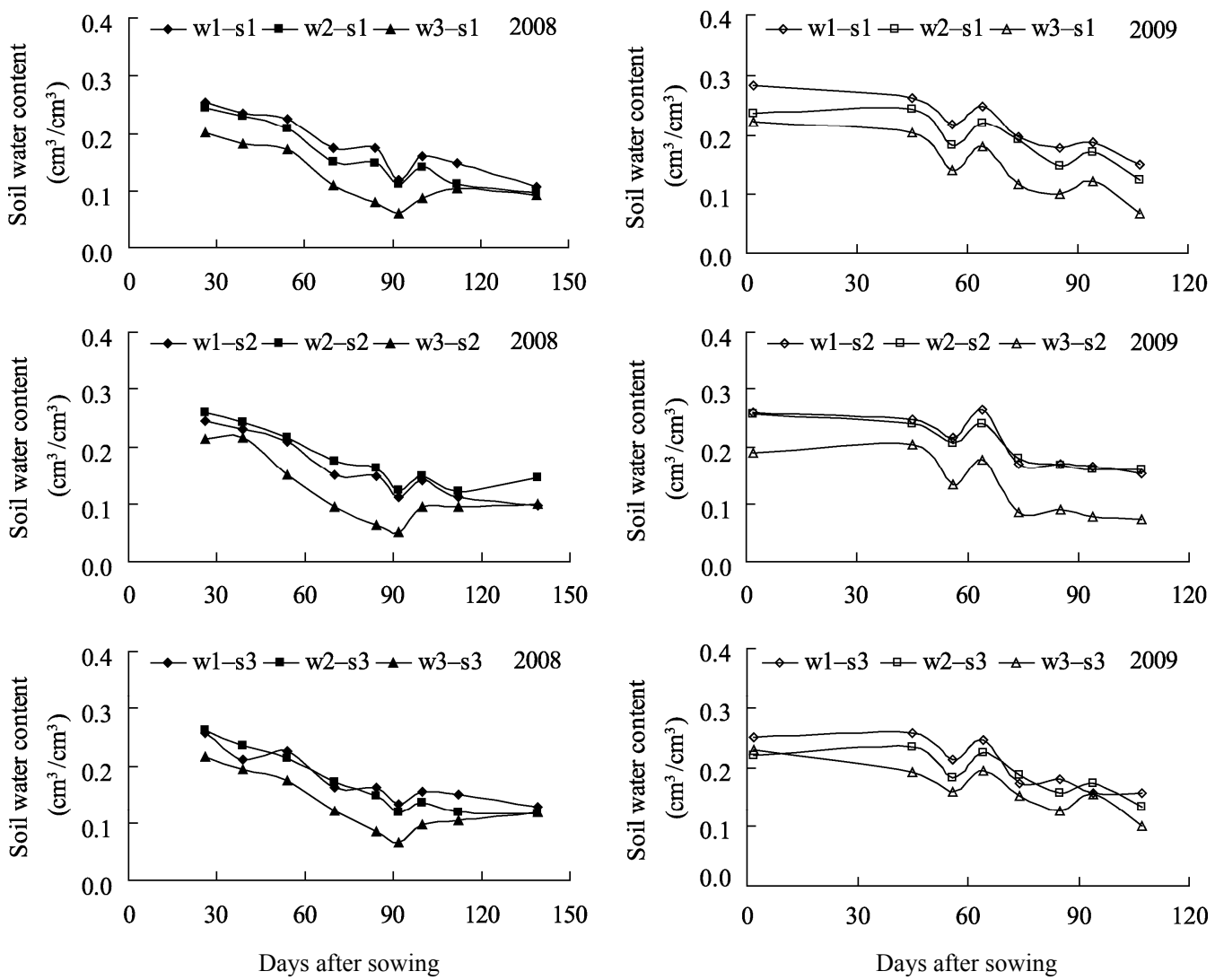

Fig. 1 Soil water content of $0-120 \mathrm{~cm}$ through wheat growth period
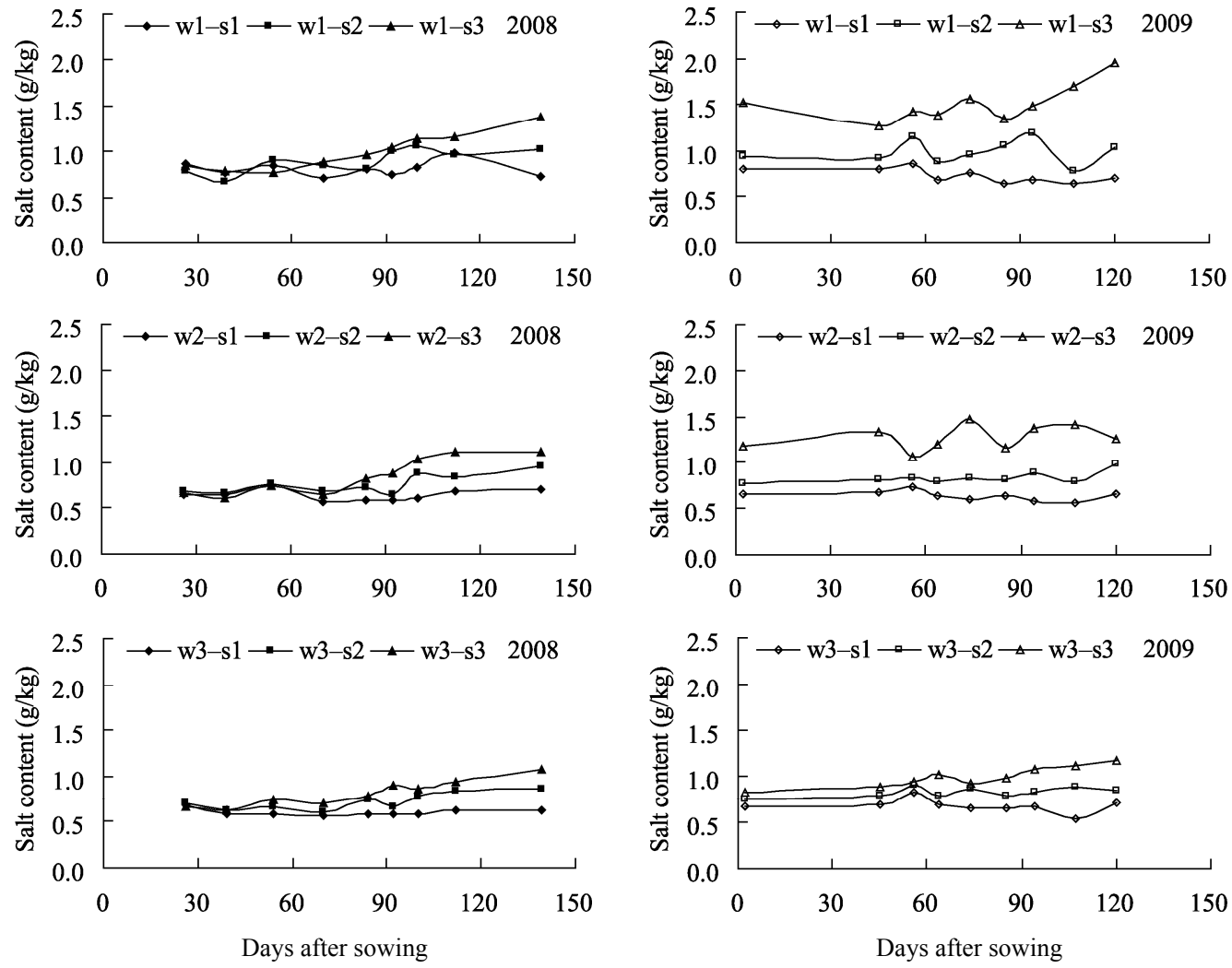

Fig. 2 Soil salt content of $0-120 \mathrm{~cm}$ through wheat growth period 
Water treatment w3 markedly decreased the pre-dawn leaf water potential after the first irrigation during the two-year period (Fig. 3). Difference in the water levels appeared from about 70 and 40 days after sowing in 2008 and 2009, respectively. Sufficient irrigation did not always guarantee higher leaf water potential, as compared to moderate deficit irrigation under saline treatments (s2 and s3) in 2009. Difference among saline treatments appeared from about 50 days after sowing in both two years. Only $6.1 \mathrm{dS} / \mathrm{m}$ treatment (s3) lowered pre-dawn leaf water potential obviously in some stages. Water salinity of $3.2 \mathrm{dS} / \mathrm{m}$ did not induce salt stress in most stages.

\subsubsection{Daily evapotranspiration}

The effects of saline irrigation on daily evapotranspiration $\mathrm{ET}_{\mathrm{d}}$ were not marked in the two-year period.
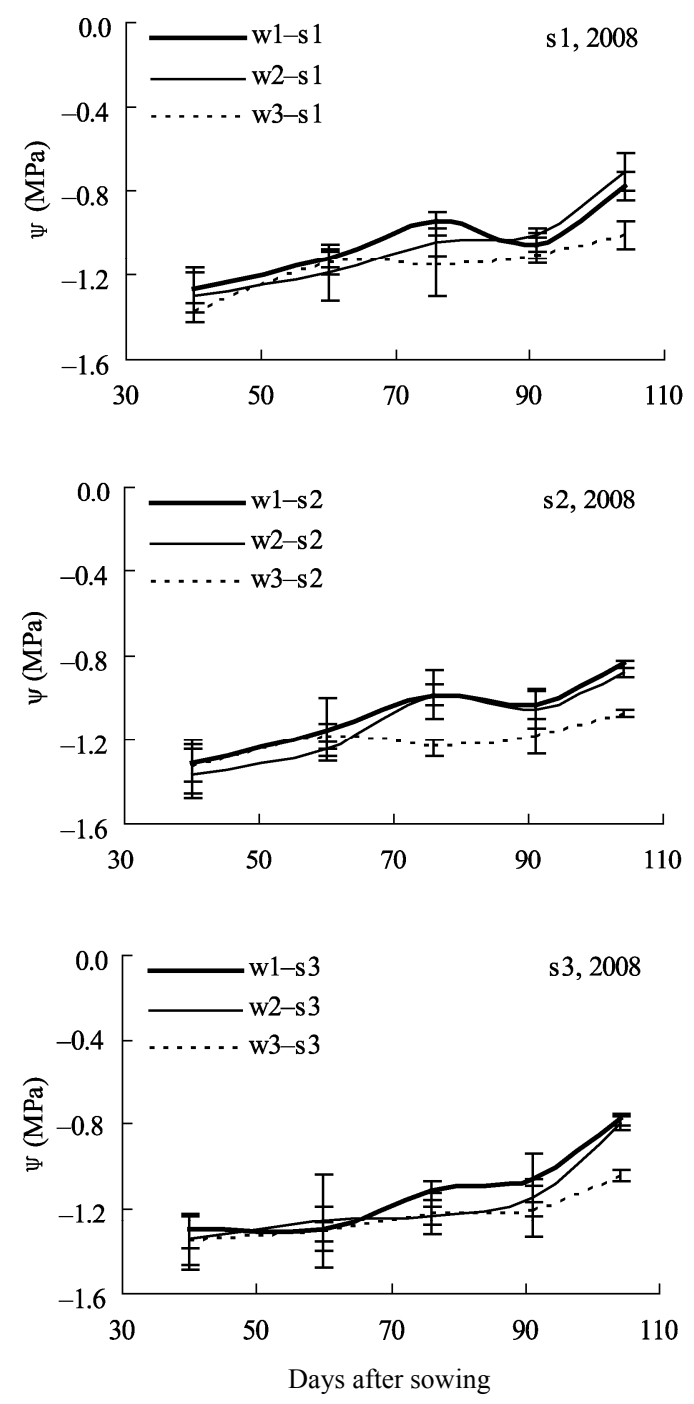

However, the differences in $\mathrm{ET}_{\mathrm{d}}$ between sufficient and deficit irrigations were significant (Fig. 4). Differences were observed since the beginning of the jointing stage, and were significant in the heading and grain-filling stages, corresponding to lower pre-dawn leaf water potential. In 2008, the sharp decline of daily evapotranspiration in $\mathrm{w} 3$ treatments from heading was due to the low soil water content in this stage as presented in Fig.1.

\subsubsection{Plant height}

The effects of saline irrigation were not remarkable in 2008 but significant $(P<0.05)$ from jointing in 2009. Plant height of s3 was reduced significantly from jointing in 2009. The effects of deficit irrigation were observed from jointing in 2008 and heading in 2009, although not all values were statistically significant.
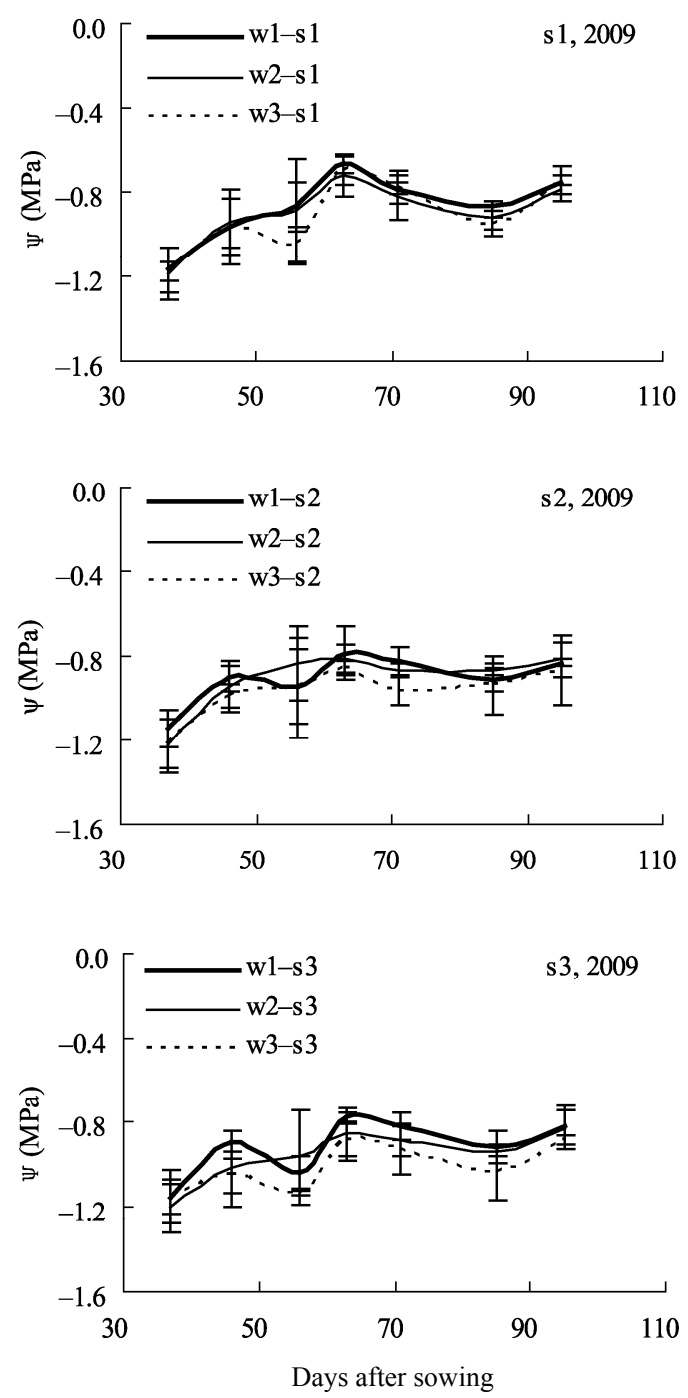

Fig. 3 Pre-dawn leaf potential of spring wheat at different days after sowing 

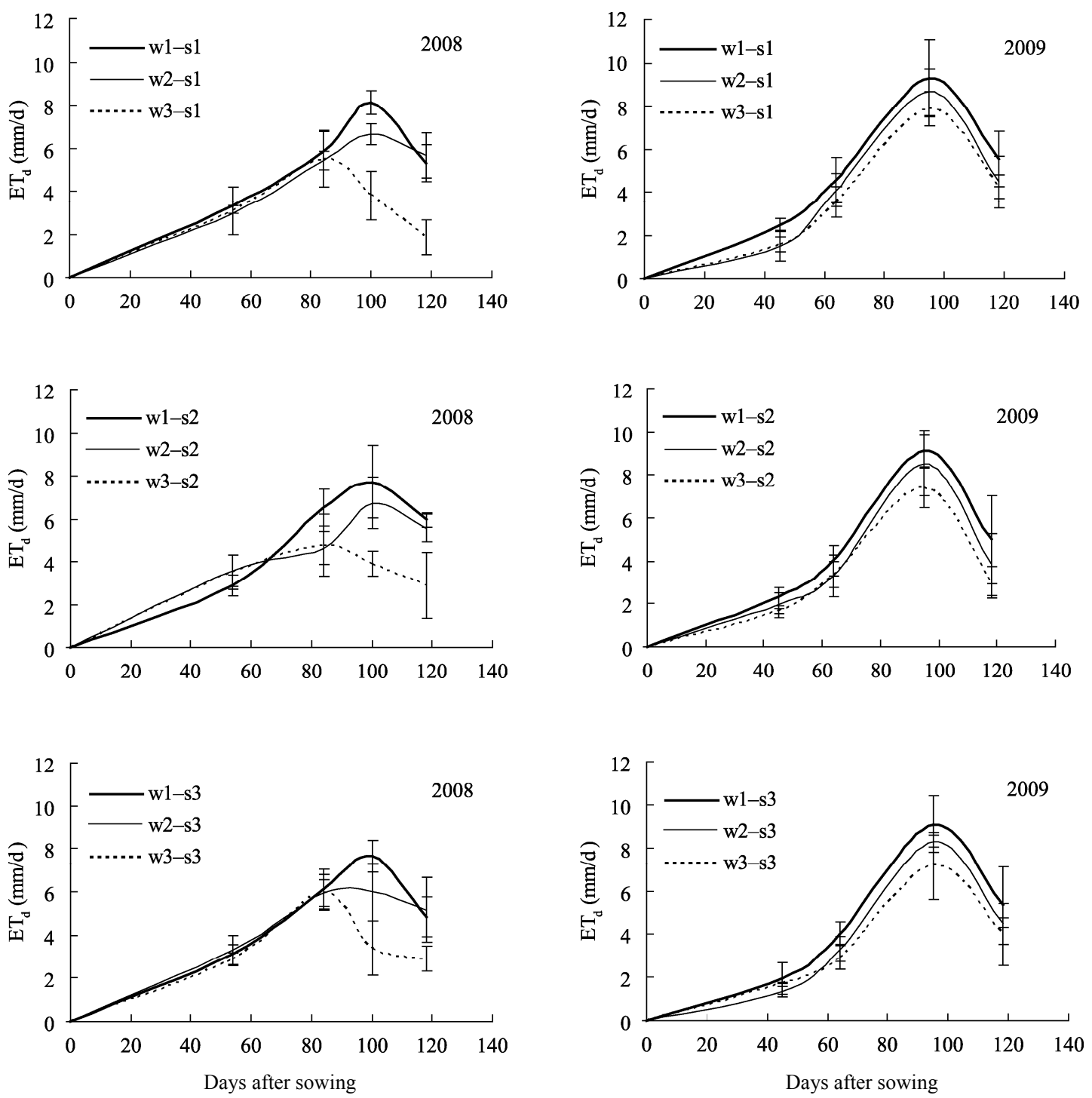

Fig. 4 Daily evapotranspiration $\left(E T_{d}\right)$ of spring wheat at different days after sowing

The height of w3 treatments from jointing was significantly reduced $(P<0.05)$ at the three salinity levels in 2008. Plant height did not always increase with the rise in water quantity in 2009, especially at higher salinity levels (s3). The combined effects of deficit and saline irrigation on plant height were significant $(P<0.05)$ during the grain-filling and maturity stages in 2008 and 2009, respectively. Whether under deficit or saline irrigation, or the combination of the two, the reduction in plant height was less than $15 \%$ compared with the maximum value of all treatments.

2.2.4 Leaf area index (LAI)

LAI is related to photosynthesis and transpiration, and to a certain extent, to the above-ground biomass of the stand and yield (Kang et al., 2005). Compared with fresh water treatments at each water level, differences in LAI under saline treatments appeared from the booting stage in 2008 and jointing stage in 2009 (Fig. 5), respectively. In 2008, when LAI reached the maximum level in each treatment, the highest LAI was higher in the fresh water treatment (s1) than in saline treatments (s2 and s3). LAI decreased with increasing water salinity under sufficient irrigation (w1) in 2009. However, a higher LAI was not always obtained by lower salinity level under deficit irrigation. LAI decreased with the reduction of water quantity from the heading stage in 2008 (Fig. 5). Treatment w3 led to earlier senescence from about 70 days after 

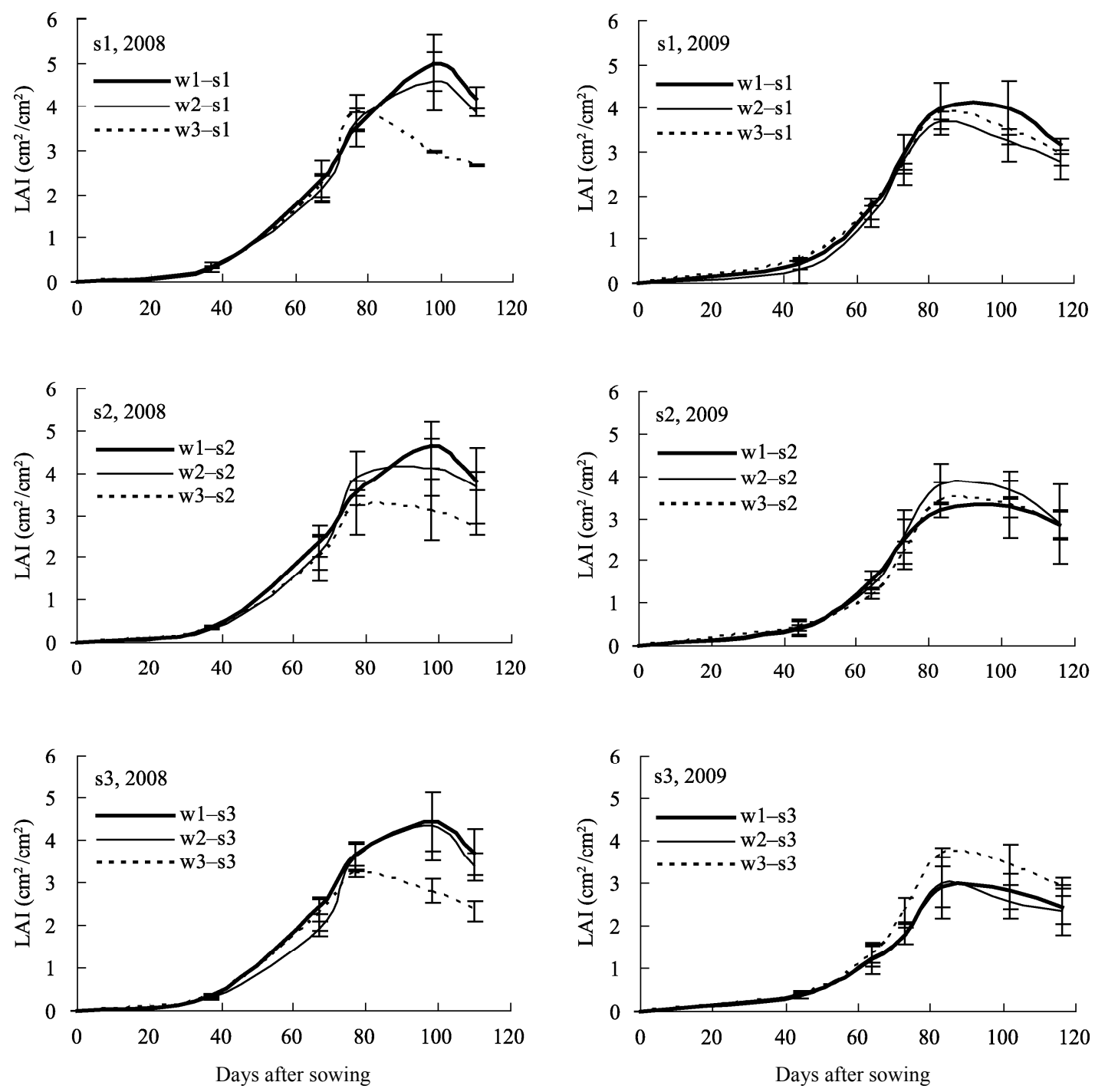

Fig. 5 LAl of spring wheat at different days after sowing

sowing in 2008. In relation, LAI decreased sharply from the late heading stage. Nevertheless, LAI of moderate water deficit (w2) and sufficient (w1) treatments retained at their high levels during the grain-filling stage. The differences in LAI between sufficient and deficit irrigations were dissimilar in the second year. Treatments except w1-s1 and w1-s2 generated a reduction in LAI from about 80 days after sowing in 2009. LAI of deficit treatments (w2 and w3) was not always lower than that of sufficient treatment (w1) under saline conditions (s2 and s3), especially at $6.1 \mathrm{dS} / \mathrm{m}$ (s3) salinity level. The effects of the combined deficit and saline irrigation on LAI showed insignificant results $(P<0.05)$ during the two-year study.

\subsection{Yield and yield attributes}

Different responses of wheat to deficit and saline irrigation at certain levels were observed in both years. The maximum yields in 2008 and 2009 were 7,432 $\mathrm{kg} / \mathrm{hm}^{2}$ and $7,223 \mathrm{k} / \mathrm{hm}^{2}$, respectively, both of which were obtained by sufficient irrigation with fresh water.

Table 4 showed the result of yields, yield components and the calculated values of harvest index (HI) and harvest ratio (HR) for all treatments. In the first year, deficit irrigation significantly influenced grain number per panicle, kernel weight per panicle, weight of 1,000 grains, above-ground dry matter, and yield. In the second year, sterility spike rate and grain number per panicle were significantly affected by deficit 
irrigation. The effect of saline irrigation was significant on the spike length only in 2009. However, the effect of saline-deficit interaction was insignificant on all variables during the two-year study.

The result of Tukey's test showed that the effect of saline irrigation on all aspects was insignificant $(P<0.05)$ in 2008. Only at water level of w3, the water salinity of $6.1 \mathrm{dS} / \mathrm{m}$ led to significant reduction in spike length in 2009. Yield increased with decreasing water salinity only under sufficient irrigation (w1). Salinity had an adverse effect on spike length, sterility spike rate, spikelet number per panicle, and kernel weight per panicle, especially at $6.1 \mathrm{dS} / \mathrm{m}$ water salinity level (s3). The weight of 1,000 grains even increased with water salinity at the water level of w3. Differences in yield induced by water salinity were not more than $10 \%$ at the same water quantity level.

In 2008, the w3 treatment showed significant decrease $(P<0.05)$ in yield, above-ground dry matter and kernel weight per panicle as compared to the w1 treatment at $\mathrm{s} 3$ water salinity level. The result of Tukey's test showed that the effect of deficit irrigation on

Table 4 Yield contributes, yields, harvest indices, and harvest ratios of spring wheat in 2008 and 2009

\begin{tabular}{|c|c|c|c|c|c|c|c|c|}
\hline & \multicolumn{4}{|c|}{2008} & \multicolumn{4}{|c|}{2009} \\
\hline & & s1 & s2 & s3 & & s1 & s2 & s3 \\
\hline \multirow{3}{*}{ Spike length $(\mathrm{cm})$} & w1 & 8.26 & 7.82 & 7.80 & w1 & 8.31 & 8.04 & 7.60 \\
\hline & w2 & 8.11 & 8.00 & 7.55 & w2 & 8.23 & 8.49 & 7.90 \\
\hline & w3 & 7.71 & 7.79 & 7.77 & w3 & 8.23 & 8.20 & 7.71 \\
\hline \multirow{3}{*}{ Sterility spike rate $(\%)$} & w1 & 15.78 & 20.26 & 15.62 & w1 & 7.02 & 8.03 & 8.28 \\
\hline & w2 & 18.12 & 20.09 & 19.86 & w2 & 9.11 & 9.83 & 9.98 \\
\hline & w3 & 20.41 & 19.55 & 18.98 & w3 & 10.03 & 11.23 & 12.48 \\
\hline \multirow{3}{*}{ Grain number per panicle (nos) } & w1 & 32.67 & 25.15 & 31.30 & w1 & 36.02 & 34.22 & 33.50 \\
\hline & w2 & 29.75 & 27.83 & 27.32 & w2 & 32.72 & 32.57 & 32.75 \\
\hline & w3 & 26.13 & 22.15 & 18.34 & w3 & 31.75 & 29.50 & 28.75 \\
\hline \multirow{3}{*}{ Kernel weight per panicle (g) } & w1 & 1.62 & 1.30 & 1.61 & w1 & 1.76 & 1.64 & 1.56 \\
\hline & w2 & 1.42 & 1.40 & 1.36 & w2 & 1.59 & 1.56 & 1.60 \\
\hline & w3 & 1.03 & 0.90 & 0.84 & w3 & 1.48 & 1.41 & 1.46 \\
\hline \multirow{3}{*}{ Weight of 1,000 grains (g) } & w1 & 49.55 & 49.35 & 48.16 & w1 & 48.37 & 48.62 & 48.18 \\
\hline & w2 & 50.52 & 51.02 & 50.41 & w2 & 49.41 & 48.74 & 49.16 \\
\hline & w3 & 40.58 & 41.99 & 45.07 & w3 & 47.47 & 47.82 & 49.07 \\
\hline \multirow{3}{*}{ Above-ground dry matter per plant $(\mathrm{g})$} & w1 & 3.16 & 2.56 & 3.29 & w1 & 3.29 & 3.00 & 2.82 \\
\hline & w2 & 2.96 & 2.89 & 2.62 & w2 & 3.01 & 2.85 & 2.87 \\
\hline & w3 & 2.25 & 1.93 & 1.78 & w3 & 2.78 & 2.55 & 2.63 \\
\hline \multirow{3}{*}{ Yield $\left(\mathrm{kg} / \mathrm{hm}^{2}\right)$} & w1 & 7,432 & 7,245 & 7,084 & w1 & 7,223 & 6,639 & 6,581 \\
\hline & w2 & 7,004 & 6,737 & 7,074 & w2 & 7,012 & 6,836 & 7,062 \\
\hline & w3 & 5,357 & 5,542 & 5,246 & w3 & 7,121 & 6,486 & 6,402 \\
\hline \multirow{3}{*}{ Harvest index $(\mathrm{g} / \mathrm{g})$} & w1 & 0.34 & 0.34 & 0.33 & w1 & 0.35 & 0.35 & 0.36 \\
\hline & w2 & 0.32 & 0.33 & 0.34 & w2 & 0.35 & 0.35 & 0.36 \\
\hline & w3 & 0.31 & 0.32 & 0.32 & w3 & 0.35 & 0.36 & 0.36 \\
\hline \multirow{3}{*}{ Harvest ratio $(\mathrm{g} / \mathrm{g})$} & w1 & 0.51 & 0.51 & 0.49 & w1 & 0.53 & 0.55 & 0.55 \\
\hline & w2 & 0.48 & 0.48 & 0.52 & w2 & 0.53 & 0.55 & 0.56 \\
\hline & w3 & 0.46 & 0.47 & 0.47 & w3 & 0.53 & 0.55 & 0.55 \\
\hline
\end{tabular}

Note: w1, w2 and w3 denote water levels of $100 \%, 80 \%$, and $60 \% \mathrm{ET}_{\mathrm{c}}$, respectively; s1, s2 and s3 denote water salinity levels of $0.65,3.2$ and $6.1 \mathrm{dS} / \mathrm{m}$, respectively. 
all levels was statistically insignificant $(P<0.05)$ in 2009. Under s2 and s3 treatments, moderate deficit irrigation (w2) obtained the highest yield in the second year. In both two years, moderate water deficit (w2) led to unobvious decrease in yield attributes; even some indices, such as the weight of 1,000 grains, were higher as compared to those found in the sufficient treatment (w1) at three salinity levels.

Minor differences in harvest index and harvest ratio indicated that the proportion accumulation of assimilation to grain was affected insignificantly by deficit and saline irrigation. Maximum values of $\mathrm{HI}$ and $\mathrm{HR}$ were obtained by irrigation treatment at $80 \% \mathrm{ET}_{\mathrm{c}}$ with salinity of $6.1 \mathrm{dS} / \mathrm{m}$ (w2-s3). In most treatments, HI and HR increased together with water salinity at the same water quantity level, which is mainly due to the lower weight of vegetative organs obtained under higher saline treatments.

\section{Discussion}

The results of the research indicated that the effect of deficit irrigation was predominated in this study. However, the effect of saline irrigation was insignificant in most treatments. Saline water in the experiment was mainly saline water. Gupta (1992) concluded the threshold salinity of irrigation water for wheat was $7 \mathrm{dS} / \mathrm{m}$. Chauhan et al. (2008) also reported that groundwater with salinity of less than $8 \mathrm{dS} / \mathrm{m}$ could be used for post-plant irrigation. Compared to the threshold salinity of irrigation water ranging from 6 to $9 \mathrm{dS} / \mathrm{m}$ for wheat (Maas and Grattan, 1999), water salinities of 3.2 and $6.1 \mathrm{dS} / \mathrm{m}$ were not so high. Furthermore, soil salinity in the two-year study was lower than the threshold soil salinity $(6 \mathrm{dS} / \mathrm{m})$ reported by Maas and Hoffman (1977). Therefore, the effect of saline irrigation was unobvious in this study. In addition, the combined effects of saline and deficit irrigation on yield and its attributes were also not statistically significant.

Plants decrease their own water potential to extract more water from soil when experiencing water and salt stresses. In this study, w3 and s3 markedly lowered pre-dawn leaf potential. The threshold value of pre-dawn leaf potential taken from field surveys was about -0.4 MPa (Itier et al., 1992; Katerji et al., 2009). In our study, a pre-dawn leaf potential of less than $-1.0 \mathrm{MPa}$ was detrimental to wheat growth. The dif- ferences in leaf potential between this study and previous researches may be explained by the variation in wheat species and methods of measurement. Lowest leaf potential for w3 treatments in 2008 was corresponding to the lowest soil water content, which was less than the lower limit of moderate soil water content.

One of the first responses of a plant to water stress is the reduction in leaf area surface in order to cut down transpiration, as proven by many researchers (Saab and Sharp, 1989; El Hafid et al., 1998; Granier and Tardieu, 1999; Anyia and Herzog, 2004; Katerji et al., 2009; Yang et al., 2009). LAI for w3 treatments reduced considerably from about 70 days after sowing in 2008, while most treatments (except w1-s1 and w1-s2) showed a reduction in LAI from about 80 days after sowing in 2009. This drastic difference in the trend of variation between the years was mainly due to the salt accumulation and the interaction of deficit and saline irrigation. During 2009, under fresh water irrigation, LAI of w1-s1 was the highest; the difference between w2-s1 and w3-s1 was statically insignificant. Under water salinity of $3.2 \mathrm{dS} / \mathrm{m}$ (s2), w2-s2 got the highest LAI; the water quantity of w1-s2 was even more than w2-s2, and simultaneously, more salt was also brought into soil in w1-s2; meanwhile, the water deficit of w3-s2 was more severe than that of w2-s2. All the above resulted in the highest LAI for w2-s2. Under the water salinity of $6.1 \mathrm{dS} / \mathrm{m}$ (s3), the irrigation water quantities of $\mathrm{w} 1-\mathrm{s} 3$ and $\mathrm{w} 2-\mathrm{s} 3$ were more than that of $\mathrm{w} 3-\mathrm{s} 3$, and the soil salinity of $\mathrm{w} 3-\mathrm{s} 3$ was the highest (Fig. 2). As salt accumulated, the effect of soil salinity was more pronounced. Therefore, the highest LAI was obtained by w3-s3.

Ali et al. (2007) indicated that yield is a function of yield components. Reduction in yield was associated with decrease in individual traits of yield components. In our study, yield decrease in moderate deficit irrigation was a result of the decline in grain number. However, under severe water-deficit conditions, grain number and grain weight were both identified as limiting factors. In both 2008 and 2009, the highest yield was obtained by sufficient irrigation with fresh water. The results indicated that maximum yield under saline irrigation cannot achieve the maximum yield under fresh water irrigation. A similar phenomenon was also reported by earlier researches (Shani and Dudley, 2001; Singh et al., 2009). However, under saline irri- 
gation, the weight of 1,000 grains and yield followed the order w2 > w1 > w3 in 2009. This implied that saline water irrigation in the second year began to affect the response of wheat yield to water level. The results showed that the maximum yield and the corresponding irrigation water quantity for saline water were less than those for fresh water.

Zhang et al. (1998) reported that the early senescence was induced by water deficit and the initiation of the whole plant senescence was necessary for the wheat to store carbohydrates in stems and for the leaf sheaths to be re-mobilized and transferred to their grains, and therefore ensure an improved HI. However, water deficit in our study was not merely at a certain stage alone, but across the entire growth period of wheat. On the other hand, the barely observable effect of deficit irrigation on $\mathrm{HI}$ and HR in our study suggested that grain-filling might be not related to the re-mobilization and transformation of carbohydrates. Palta et al. (1994) and Yang et al. (2003) have reported early senescence induced by water deficit. The corresponding trend of LAI and $\mathrm{ET}_{\mathrm{d}}$ in our study demonstrated that the response of leaves did not change with water salinity under deficit irrigation. The results also indicated that booting to grain-filling stages were the most sensitive stages in this area.

The effect of deficit irrigation on wheat growth showed a clear difference under saline conditions in 2008 and 2009. In 2009, the maximum height, LAI, and pre-dawn leaf water potential were achieved consistently by deficit irrigation at 3.2 and $6.1 \mathrm{dS} / \mathrm{m}$. These occurrences were due to increased salt accumulation under sufficient irrigation with saline water. The findings on the wheat growth parameters implied that irrigation with increasing water quantity might not be a positive choice when poor quality water has been utilized for a long time. On the contrary, moderate deficit irrigation seemed to be more advisable for spring wheat growth when using saline water.

\section{Conclusions}

The results of this study provide relevant information on irrigation management. First, the effect of deficit irrigation was predominated while the effects of saline irrigation and the combined deficit saline irrigation were insignificant. However, the effect of saline irri- gation gradually increased with prolonged application of saline water. Second, wheat was sensitive at the heading to grain-filling stages based on the development of LAI and $\mathrm{ET}_{\mathrm{d}}$. Third, the maximum yield and the corresponding irrigation water quantity for saline water were less than those for fresh water. Therefore, for a long-term use of saline water, sufficient irrigation is not a suitable choice for maximizing yield and water productivity. Instead, water supply of $80 \% \mathrm{ET}_{\mathrm{c}}$ with the salinity of less than $3.2 \mathrm{dS} / \mathrm{m}$ is feasible in improving water productivity without significantly decreasing yield.

\section{Acknowledgements}

This research was supported by the National Basic Research Program of China (2011CB403406), the National Natural Science Foundation of China (51179166) and the Youth Foundation of Taiyuan University of Technology (2012L077).

\section{References}

Ali M H, Hoque M R, Hassan A A, et al. 2007. Effects of deficit irrigation on yield, water productivity, and economic returns of wheat. Agricultural Water Management, 92: 151-161.

Anyia A O, Herzog H. 2004. Water-use efficiency, leaf area and leaf gas exchange of cowpeas under mid-season drought. European Journal of Agronomy, 20: 327-339.

Ayars J E, Hutmacher R B, Schoneman R A, et al. 1993. Long term use of saline water for irrigation. Irrigation Science, 14: 27-34.

Ayers R S, Westcot D W. 1985. Water Quality for Agriculture. Irrigation and Drainage Paper 29 (revised 1). Rome: Food and Agriculture Organization of the United Nations.

Ben-Asher J, Tsuyuki I, Bravdo B A. 2006a. Irrigation of grapevines with saline water I. Leaf area index, stomatal conductance, transpiration and photosynthesis. Agricultural Water Management, 83: 13-21.

Ben-Asher J, van Dam J, Feddes R A, et al. 2006b. Irrigation of grapevines with saline water II. Mathematical simulation of vine growth and yield. Agricultural Water Management. 83: 22-29.

Cai X M, Rosegrant M W. 2003. World water productivity: current situation and future options. In: Kijne J W, Barker R, Molden D. Water Productivity in Agriculture: Limits and Opportunities for Improvement. Oxford: $\mathrm{CAB}$ Publishing and Colombo: International Water Management Institute, 163-178.

Chauhan C P S, Singh R B, Gupta S K. 2008. Supplemental irrigation of wheat with saline water. Agricultural Water Management, 95: 253-258.

Chen Y Q, Li X B, Wang J. 2011. Changes and effecting factors of 
grain production in China. Chinese Geographical Science, 21(6): 676-684.

Datta K K, Sharma V P, Sharma D P. 1998. Estimation of a production function for wheat under saline conditions. Agricultural Water Management, 36: 85-94.

De Pascale S, Barbieri G. 1995. Effects of soil salinity from long-term irrigation with saline-sodic water on yield and quality of winter vegetable crops. Scientia Horticulturae, 64: 145-157.

El Hafid R, Smith D H, Karrou M, et al. 1998. Morphological attributes associated with early-season drought tolerance in spring durum wheat in a Mediterranean environment. Euphytica, 101: 273-282.

Farré I, Faci J M. 2006. Comparative response of maize (Zea mays L.) and sorghum (Sorghum bicolor L. Moench) to deficit irrigation in a Mediterranean environment. Agricultural Water Management, 83: 135-143.

Granier C, Tardieu F. 1999. Water deficit and spatial pattern of leaf development. Variability in responses can be simulated using a simple model of leaf development. Plant Physiology, 119: 609-619.

Gupta S K. 1992. Leaching of Salt Affected Soils. Technical Bulletins No. 17. Karnal: Central Soil Salinity Research Institute, 71.

Howell T A. 2001. Enhancing water use efficiency in irrigated agriculture. Agronormy Journal, 93: 281-189.

Itier B, Flura D, Belabbes K, et al. 1992. Relations between relative evapotranspiration and pre-dawn leaf water potential in soybean grown in several locations. Irrigation Science, 13: 109-114.

Jalota S K, Sood A, Chahal G B S, et al. 2006. Crop water productivity of cotton (Gossypium hirsutum L.) -wheat (Triticum aestivum L.) system as influenced by deficit irrigation, soil texture and precipitation agricultural water management. Agricultural Water Management, 84: 137-146.

Kang Y H, Wang Q G, Liu H J. 2005. Winter wheat canopy interception and its influence factors under sprinkler irrigation. Agricultural Water Management, 74: 189-199.

Katerji N, van Hoorn J W, Hamdy A, et al. 1998. Salinity and drought, a comparison of their effects on the relationship between yield and evapotranspiration. Agricultural Water Management, 36: 45-54.

Katerji N, van Hoorn J W, Hamdy A, et al. 2000. Salt tolerance classification of crops according to soil salinity and to water stress day index. Agricultural Water Management, 43: 99-109.

Katerji N, Mastrorilli M, van Hoorn J W, et al. 2009. Durum wheat and barley productivity in saline-drought environments. European Journal of Agronomy, 31: 1-9.

Khosla B K, Gupta R K. 1997. Response of wheat to saline irrigation and drainage. Agricultural Water Management, 32: 285-291.

Maas E V, Hoffman G J. 1977. Crop salt tolerance-current assessment. Journal of the Irrigation and Drainage Division, 103: 114-134.

Maas E V, Grattan S R. 1999. Crop yields as affected by salinity. In:
Skaggs R W, van Schilfgaarde J. Agricultural Drainage. Agronomy Monograph 38. Madison: ASA-CSSA-SSSA, 55-108.

Malash N, Flowers T J, Ragab R. 2005. Effect of irrigation systems and water management practices using saline and non-saline water on tomato production. Agricultural Water Management, 78: 25-38.

Mao X S, Liu M Y, Wang X Y, et al. 2003. Effects of deficit irrigation on yield and water use of greenhouse grown cucumber in the North China Plain. Agricultural Water Management, 61: 219-228.

Ould Ahmed B A, Yamamoto T, Rasiah V, et al. 2007. The impact of saline water irrigation management options in a dune sand on available soil water and its salinity. Agricultural Water Management, 88: 63-72.

Palta J A, Kobata T, Turner N C, et al. 1994. Remobilization of carbon and nitrogen in wheat as influenced by postanthesis water deficits. Crop Science, 34: 118-124.

Panda R K, Behera S K, Kashyap P S. 2003. Effective management of irrigation water for wheat under stressed conditions. Agricultural Water Management, 63: 37-56.

Saab I N, Sharp R E. 1989. Non-hydraulic signals from maize roots in drying soil: inhibition of leaf elongation but not stomatal conductance. Planta, 179: 466-474.

Shalhevet J. 1994. Using water of marginal quality for crop production: major issues. Agricultural Water Management, 25: 233-269.

Shani U, Dudley L M. 2001. Field studies of crop response to water and salt stress. Soil Science Society of America Journal, 65: $1522-1528$.

Singh R B, Chauhan C P S, Minhas P S. 2009. Water production functions of wheat (Triticum aestivum $\mathrm{L}$.) irrigated with saline and alkali waters using double-line source sprinkler system. Agricultural Water Management, 96: 736-744.

Tedeschi A, Menenti M. 2002. Simulation studies of long term saline water use: model validation and evaluation of schedules. Agricultural Water Management, 54: 123-157.

van Hoorn J W, Katerji N, Hamdy A, et al. 1993. Effect of saline water on soil salinity and on water stress, growth, and yield of wheat and potatoes. Agricultural Water Management, 23: 247-265.

Yang J C, Zhang J H, Wang Z Q, et al. 2003. Postanthesis water deficits enhance grain filling in two-line hybrid rice. Crop Science, 43: 2099-2108.

Yang Y, Timlin D J, Fleisher D H, et al. 2009. Simulating leaf area of corn plants at contrasting water status. Agricultural and Forest Meteorology, 149: 1161-1167.

Zhang B C, Li F M, Huang G B, et al. 2006. Yield performance of spring wheat improved by regulated deficit irrigation in an arid area. Agricultural Water Management, 79: 28-42.

Zhang J H, Sui X Z, Li B, et al. 1998. An improved water-use efficiency for winter wheat grown under reduced irrigation. Field Crops Research, 59: 91-98. 